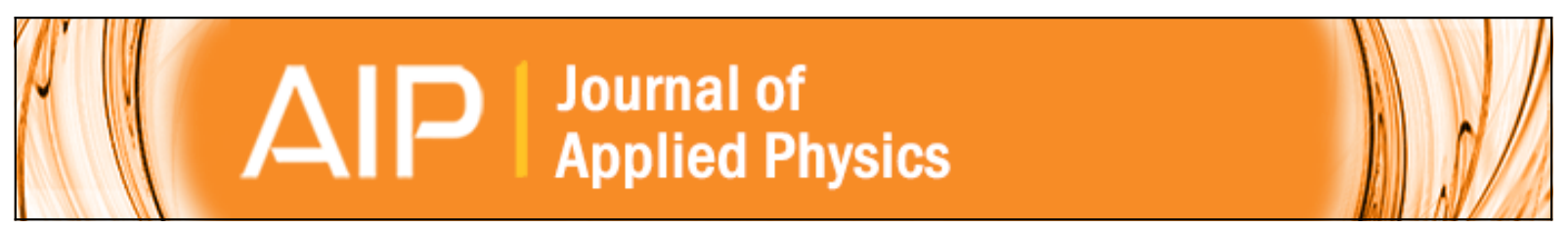

Compression of scheelite-type SrMoO4 under quasi-hydrostatic conditions: Redefining the high-pressure structural sequence

D. Errandonea, L. Gracia, R. Lacomba-Perales, A. Polian, and J. C. Chervin

Citation: Journal of Applied Physics 113, 123510 (2013); doi: 10.1063/1.4798374

View online: http://dx.doi.org/10.1063/1.4798374

View Table of Contents: http://scitation.aip.org/content/aip/journal/jap/113/12?ver=pdfcov

Published by the AIP Publishing

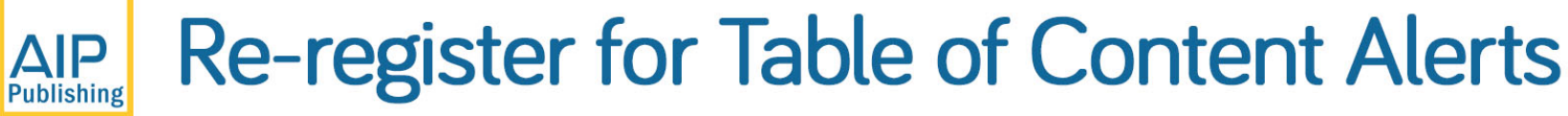

Create a profile.

Sign up today! 


\title{
Compression of scheelite-type $\mathrm{SrMoO}_{4}$ under quasi-hydrostatic conditions: Redefining the high-pressure structural sequence
}

\author{
D. Errandonea, ${ }^{1}$ L. Gracia, ${ }^{2}$ R. Lacomba-Perales, ${ }^{1}$ A. Polian, ${ }^{3}$ and J. C. Chervin ${ }^{3}$ \\ ${ }^{1}$ Departamento de Física Aplicada-ICMUV, Universidad de Valencia, MALTA Consolider Team, \\ Edificio de Investigación, C. Dr. Moliner 50, 46100 Burjassot, Spain \\ ${ }^{2}$ Departament de Química Física I Analítica, MALTA Consolider Team, Universitat Jaume I, \\ Campus de Riu Sec, 12080 Castelló, Spain \\ ${ }^{3}$ Institut de Minéralogie et de Physique des Milieux Condensés, Université Pierre et Marie Curie-Sorbonne \\ Universités, CNRS UMR 7590, 4 Place Jussieu, F-75252 Paris Cedex 05, France
}

(Received 17 December 2012; accepted 13 March 2013; published online 29 March 2013)

\begin{abstract}
The high-pressure behavior of tetragonal $\mathrm{SrMoO}_{4}$ was analyzed by Raman and optical-absorption measurements. Pressures up to $46.1 \mathrm{GPa}$ were generated using diamond-anvil cells and $\mathrm{Ne}$ or $\mathrm{N}_{2}$ as quasi-hydrostatic pressure-transmitting media. A reversible phase transition is observed at 17.7 GPa. A second transition is found at $28.8 \mathrm{GPa}$ and the onset of a third one at $44.2 \mathrm{GPa}$. The pressure dependence of Raman-active modes is reported for the different phases and the pressure evolution of the fundamental band-gap reported for the low-pressure phase. The observed changes in the Raman spectra contradict the structural sequence determined from previous experiments performed under higher non-hydrostaticity. This fact suggests that deviatoric stresses can influence pressure-driven transitions in scheelite-type oxides. We also report total-energy, lattice-dynamics, and band-structure calculations. They reproduce accurately the behavior of the physical properties of the low-pressure phase and predict the occurrence of phase transitions at pressures similar to experimental transition pressures. According to theory, the high-pressure phases have monoclinic and orthorhombic structures, which are much more compact than tetragonal scheelite. Theoretical results and experiments are compared with previous studies. (ㅇ 2013 American Institute of Physics. [http://dx.doi.org/10.1063/1.4798374]
\end{abstract}

\section{INTRODUCTION}

Orthomolybdates are very interesting materials due to their applications. Strontium molybdate $\left(\mathrm{SrMoO}_{4}\right)$ is a prominent member of this family. It has attracted particular interest as host for lanthanide-active lasers as well as scintillator and photocatalytic material. ${ }^{1-3} \mathrm{SrMoO}_{4}$ crystallizes in the so-called scheelite structure $\left(\right.$ scheelite $\left.=\mathrm{CaWO}_{4}\right),{ }^{4}$ which belongs to the tetragonal space group (SG) $I 4_{1} / a$. The scheelite structure of $\mathrm{SrMoO}_{4}$ is shown in Fig. 1. There, it can be seen that in this structure each Mo site is surrounded by four equivalent $\mathrm{O}$ sites in approximately tetrahedral symmetry. On the other hand, each $\mathrm{Sr}$ site is surrounded by eight $\mathrm{O}$ sites forming a bisdisphenoid.

After the pioneer work of Hazen et al., ${ }^{5}$ in the last two decades several high-pressure (HP) studies have been performed in scheelite-type molybdates. ${ }^{6-13}$ They showed that compression is an efficient tool to improve the understanding of their main physical properties. ${ }^{14}$ In the case of $\mathrm{SrMoO}_{4}$, previous studies include $\operatorname{Raman}^{6}$ and x-ray diffraction experiments ${ }^{11}$ up to $37 \mathrm{GPa}$. They reported the occurrence of a pressure-driven phase transition near $13 \mathrm{GPa}$. The transition is to a monoclinic structure isomorphic to the M-fergusonite structure (SG I2/a), ${ }^{11}$ which remained stable up to the highest pressure covered by experiments. However, previous experiments have been carried out using a 4:1 methanol-ethanol mixture or silicone oil as pressure-transmitting medium, being known that non-hydrostaticity becomes important for these pressure media beyond $10 \mathrm{GPa},{ }^{15}$ i.e., pressures relevant for the studies performed in $\mathrm{SrMoO}_{4}$. This fact could probably influence the HP structural behavior of $\mathrm{SrMoO}_{4}$ as recently shown for the related oxides $\mathrm{BaWO}_{4}$ (Ref. 16) and $\mathrm{CuWO}_{4}{ }^{17}$ In them, non-hydrostatic stresses strongly influenced their HP structural sequence at pressures as low as $5 \mathrm{GPa}$ calling for a reexamination of HP studies on related oxides. With this aim, we are reporting Raman and optical-absorption measurements performed in $\mathrm{SrMoO}_{4}$ using quasi-hydrostatic pressure media $\left(\mathrm{Ne}\right.$ and $\left.\mathrm{N}_{2}\right) \cdot{ }^{15}$ In addition, we extended the pressure range covered by experiments up to $46.1 \mathrm{GPa}$. We found the existence of at least two phase transitions, having none of the HP phases the M-fergusonite structure. We also report theoretical calculations to propose candidate structures for HP phases. The results are discussed in comparison with previous investigations.

\section{EXPERIMENTAL DETAILS}

Samples used in the experiments were obtained from the single crystal described in Ref. 11. It was confirmed by x-ray diffraction and Raman spectroscopy that the crystal has only one phase with the scheelite structure. For the HP Raman experiment, a $10-\mu \mathrm{m}$-thick plate was cleaved from the crystal and loaded in a 300- $\mu \mathrm{m}$ culet diamond-anvil cell (DAC) together with ruby spheres of about $1 \mu \mathrm{m}$ in diameter. The pressure chamber consisted in a $100-\mu \mathrm{m}$ diameter hole drilled in a $200-\mu \mathrm{m}$-thick inconel gasket pre-indented to $40 \mu \mathrm{m}$. Ne was used as pressure medium and pressure was determined by the ruby fluorescence technique. ${ }^{18}$ Room-temperature Raman 

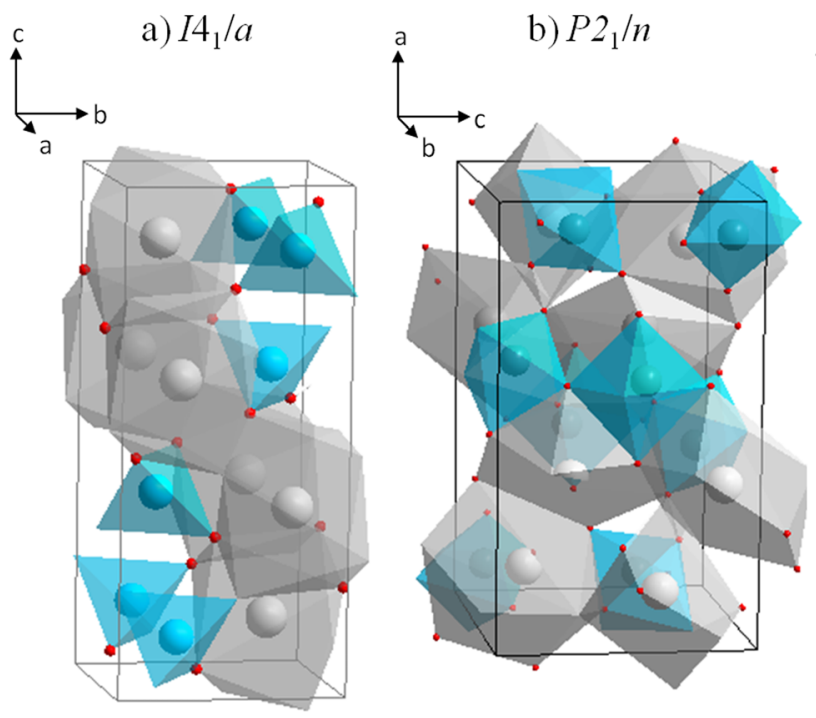

experiments were performed in the backscattering geometry using the $514.5 \mathrm{~nm}$ line of an $\mathrm{Ar}^{+}$-ion laser with a power of less than $100 \mathrm{~mW}$ before the DAC to avoid sample heating. Laser heating of the sample is also negligible because the laser energy is $2 \mathrm{eV}$ smaller than the band gap of $\mathrm{SrMoO}_{4} \cdot{ }^{3,19} \mathrm{~A}$ Mitutoyo $20 \times$ long working distance objective was employed for focusing the laser on the sample and for collecting the Raman spectra. The scattered light was analyzed with a JobinYvon T64000 triple spectrometer equipped with a confocal microscope in combination with a liquid-nitrogen cooled multichannel charge-coupled device (CCD) detector. The spectral resolution was better than $1 \mathrm{~cm}^{-1}$.

For the optical-absorption measurements, a small single crystal of $10 \mu \mathrm{m}$ thickness was cleaved. These measurements were performed at ambient pressure and upon compression. For the high-pressure studies, the crystal was loaded in a $180 \mu \mathrm{m}$ hole of a $200-\mu \mathrm{m}$-thick Inconel gasket pre-indented to $50 \mu \mathrm{m}$ in a DAC. The culet-size of the IIA-type diamond anvils was $480 \mu \mathrm{m}$. Small ruby balls were loaded together with sample for pressure determination. ${ }^{18} \mathrm{~N}_{2}$ was used as pressure medium. The absorption experiments were carried out in the ultraviolet (UV)-visible (VIS)-near-infrared (NIR) range using an optical set-up consisting of a deuterium lamp, fused silica lenses, reflecting optics objectives, and an UV-VIS-NIR spectrometer (Ocean Optics USB4000-UV-VIS, resolution $1.5 \mathrm{~nm}$ ). This set-up allows transmission measurements up to $5.5 \mathrm{eV},{ }^{20}$ i.e., up to higher energies than the absorption edge of IIA diamonds. The absorption spectra were obtained from the transmittance spectra of the sample, which were measured using the sample-in sample-out method. ${ }^{21,22}$

\section{OVERVIEW OF THE CALCULATIONS}

Calculations were performed with the CRYSTAL09 program package. ${ }^{23} \mathrm{Sr}$ and Mo atoms have been described by Hay-Wadt pseudo-potential scheme with small core, HAYWSC-311(1d)G and HAYWSC-311(d31)G basis sets, respectively, while for O atoms, the standard 6-31 G* basis set has been used. Becke's three-parameter hybrid nonlocal exchange functional, ${ }^{24}$ combined with the Lee-Yang-Parr gradient-corrected correlation c) Cmca

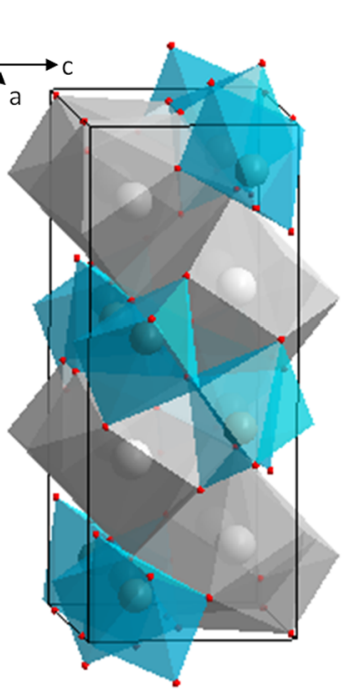

FIG. 1. Schematic view of the low-pressure scheelite structure of $\mathrm{SrMoO}_{4}$ and the proposed high-pressure monoclinic and orthorhombic structures. Blue spheres represent the Mo atoms, gray ones the $\mathrm{Sr}$, and red ones the $\mathrm{O}$. functional, B3LYP, ${ }^{25}$ has been used. This functional has been extensively used for molecules and crystalline structures, providing an accurate description of the bond lengths, phonons, binding energies, and band-gap values. ${ }^{26-28}$ All geometrical parameters and internal positions were fully optimized for the studied phases. Diagonalization of the Fock matrix was performed at adequate k-point grids in reciprocal space, with the Pack-Monkhorst/Gilat shrinking factors being $\mathrm{IS}=\mathrm{ISP}=4$. The thresholds controlling the accuracy of the calculation of Coulomb and exchange integrals were set to $10^{-8}$ and $10^{-14}$, assuring a convergence in total energy better than $10^{-7}$ a.u. in all cases, and the percent of Fock/Kohn-Sham matrix mixing was set to $40 .^{23}$ Fittings with a Birch-Murnaghan third- and second-order equation of state $(\mathrm{EOS})^{29}$ of the computed energy-volume data provide values of the zero-pressure bulk modulus $\left(\mathrm{B}_{0}\right)$ and its pressure derivative $\left(\mathrm{B}_{0}{ }^{\prime}\right)$ as well as enthalpy-pressure curves for the studied structures.

Vibrational-frequency calculations in CRYSTAL09 are performed at the $\Gamma$ point within the harmonic approximation. The vibrational analysis was performed by computing the Hessian matrix and the force constants. The calculations provided information about the frequency, symmetry, and polarization vector of the Raman modes in each structure. The band structures have been also obtained, using CRYSTAL09, along the appropriate highsymmetry paths of the Brillouin zone for scheelite structure.

In order to identify phase transitions, we carried out $a b$ initio calculations for the initial scheelite structure and several potential HP phases: fergusonite $(I 2 / a)$, monoclinic structures related to $\mathrm{BaWO}_{4}$-II and $\mathrm{LaTaO}_{4}\left(P 2_{1} / n\right.$ and $P 2_{1} / c$, respectively), and an orthorhombic structure ( $\mathrm{CmCa}$ ) among others. The structural candidates considered were selected by empirical crystal-chemistry arguments and the behavior under pressure of the cation subarrays in oxides. ${ }^{14}$

\section{EXPERIMENTAL RESULTS}

\section{A. Raman experiments}

The scheelite structure adopted by $\mathrm{SrMoO}_{4}$ at low pressure is centrosymmetric and has space group $I 4_{1} / a$ $\left(\mathrm{C}^{6}{ }_{4 \mathrm{~h}}\right.$ in Schoenflies notation) with four formula units per 
body-centered unit cell. The $\mathrm{Sr}$ and Mo atoms have $\mathrm{S}_{4}$ point symmetry and the oxygen atoms have $C_{1}$ point symmetry. Group theoretical considerations lead to 13 zone-center Raman-active modes: $\Gamma=3 \mathrm{~A}_{\mathrm{g}}+5 \mathrm{~B}_{\mathrm{g}}+5 \mathrm{E}_{\mathrm{g}}$. Fig. 2(a) shows a Raman spectrum collected at ambient pressure from $\mathrm{SrMoO}_{4}$ before loading the sample into the DAC together with a selection of the 18 Raman spectra collected up to $26.6 \mathrm{GPa}$. At ambient pressure, 12 of the 13 modes of the scheelite-type structure can be easily identified. As typical in scheelites, the most intense mode is the highest frequency mode associated to a symmetric stretching internal vibration of the $\mathrm{MoO}_{4}$ tetrahedron. One of the modes is much weaker than the other modes are $\left(236.6 \mathrm{~cm}^{-1}\right.$; see the inset in Fig. 2(a)). In addition, there is a mode much broader than the rest $\left(\sim 328 \mathrm{~cm}^{-1}\right)$. This mode consists of two modes very close in frequency, which split under compression allowing the identification of the 13 Raman modes. Table I summarizes the Raman frequencies $(\omega)$ at ambient pressure, which are compared with previous experiments ${ }^{6}$ and present and previous calculations. ${ }^{30}$ The agreement with previous studies is good. A comparison with calculations will be done in Sec. V.

According to our experiments, only 13 Raman modes are observed up to $16.6 \mathrm{GPa}$. All the modes can be assigned to the scheelite-structure. Fig. 3 summarizes the pressure evolution of all modes. The dependence of their frequencies with pressure is nearly linear. The pressure coefficients $(\partial \omega / \partial \mathrm{P})$ obtained assuming linear dependences are summarized in Table I. The reported Grüneisen parameters, $\gamma=\left(\mathrm{B}_{0} / \omega\right)$. $\partial \omega / \partial \mathrm{P}$, were calculated assuming a bulk modulus of $\mathrm{B}_{0}=71 \mathrm{GPa} .{ }^{11}$ The most characteristic features of the pressure evolution of the Raman spectrum of the scheelite phase are: Most modes harden under compression. The $\mathrm{E}_{\mathrm{g}}$ mode at $233.6 \mathrm{~cm}^{-1}$ is found to be the mode that hardens more under compression. According to our calculations, this mode is associated to an asymmetric O-Mo-O bending. On the other hand, the lowest frequency mode $\left(B_{g}\right.$ at $\left.98.1 \mathrm{~cm}^{-1}\right)$ is found to soften with pressure. According to our calculations, this mode is associated to $\mathrm{O}-\mathrm{Sr}-\mathrm{O}$ and $\mathrm{O}-\mathrm{Mo}-\mathrm{O}$ bending movements, where the displacement vector in $\mathrm{Sr}$ and Mo atoms is not negligible. The presence of this soft mode is typical of scheelite-type molibdates and tungstates. ${ }^{31}$ This remarkable behavior has been discussed in previous works being tentatively assigned to a mechanical instability induced by pressure in the scheelite structure, being possible related with the decrease upon compression of the elastic constant $\mathrm{C}_{66}{ }^{32}$ Another fact to remark is the frequency crossing taking place around $7.5 \mathrm{GPa}$ for the two phonons with frequencies of 162.8 and $183.3 \mathrm{~cm}^{-1}$ at ambient pressure. In Table I, it can be seen that non-hydrostatic experiments ${ }^{6}$ give larger pressure coefficients than our quasi-hydrostatic experiments.

Upon further compression, several modifications on the Raman spectra take place around $17.7 \mathrm{GPa}$. In particular, several extra modes appear in the low-frequency region. There are also modes that emerge in the region of the phonon-gap of scheelite $\left(400-800 \mathrm{~cm}^{-1}\right)$ and clear changes are visible in the high-frequency range (see Fig. 2(a)). In total, 42 modes are detected at $17.7 \mathrm{GPa}$. The changes observed can be assigned to the occurrence of a phase transition. In previous experiments done using less hydrostatic pressure media, the transition occurred around $13 \mathrm{GPa}{ }^{6,11}$ This suggests that the stability of the scheelite structure is reduced by at least $4 \mathrm{GPa}$ when deviatoric stresses are present. In Table II, we show the Raman-active phonons detected in phase II and their pressure coefficients. Upon compression, several modes with close frequencies tend to merge into broad bands. A Lorentzian multi-peak fitting analysis was used to deconvolute the different modes. Fig. 2(b) illustrates the identification of 42 modes for phase II at $17.7 \mathrm{GPa}$ and the Lorentzian-functions fit to the measured spectrum. In Table II, it can be seen that in phase II three phonons have negative pressure coefficients. We would also like to call the attention of the readers to the fact that the measured spectra from the HP phase under non-hydrostatic conditions ${ }^{6}$ were qualitatively different than those measured here for phase II.
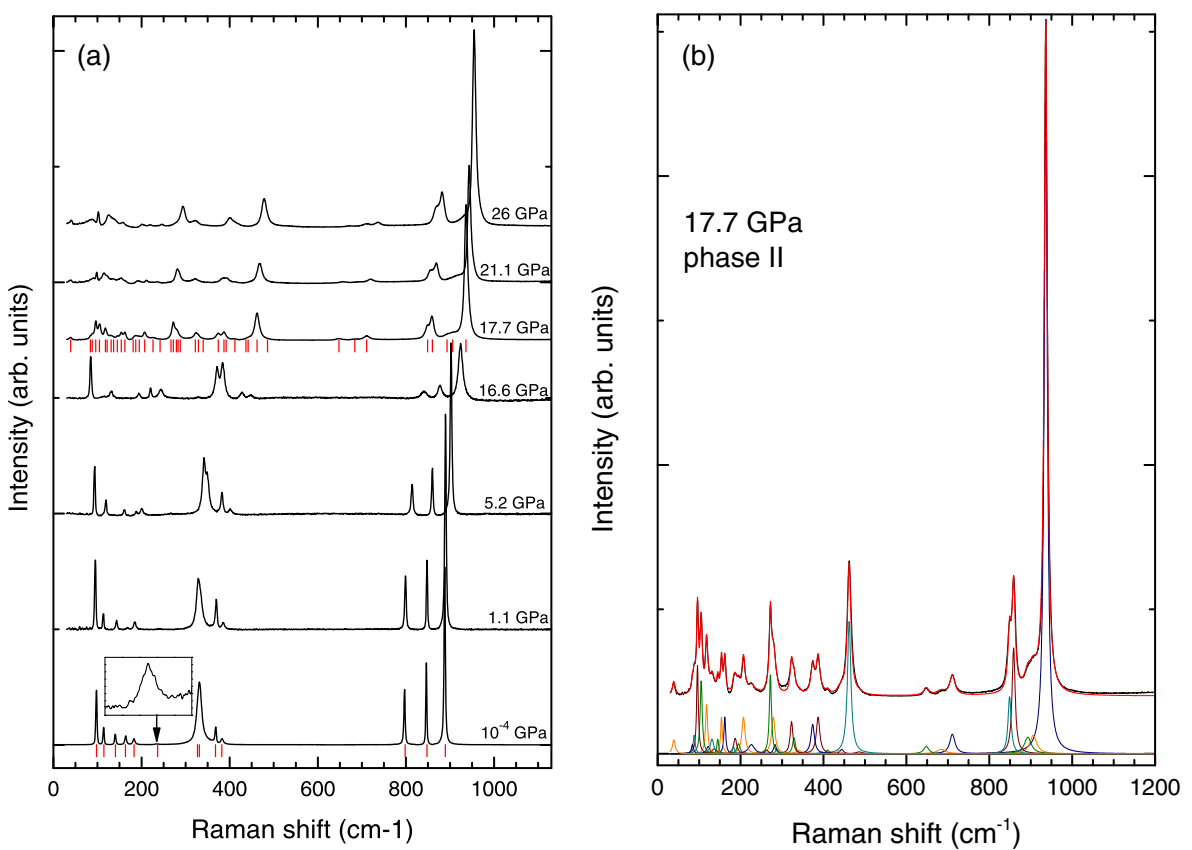

FIG. 2. (a) Selection of Raman spectra collected from ambient pressure to $26 \mathrm{GPa}$. Ticks indicate the phonons identified at $1 \mathrm{~atm}$ (scheelite) and $17.7 \mathrm{GPa}$ (phase II). (b) Lorentzian fits of 42 Raman modes at $17.7 \mathrm{GPa}$. Upper trace: Raman spectrum (black) and fit (red). Lower trace: individual Lorentzian functions. 
TABLE I. Phonon frequencies $\left(\omega_{0}\right)$ and pressure coefficients $(\mathrm{d} \omega / \mathrm{dP})$ for scheelite at ambient pressure. Grüneisen parameters $\left(\gamma=\mathrm{B}_{0} / \omega_{0} \mathrm{~d} \omega / \mathrm{dP}\right)$ are also calculated from experiments assuming $\mathrm{B}_{0}=71 \mathrm{GPa} .{ }^{11}$ Mode assignment has been made on the basis of calculations.

\begin{tabular}{|c|c|c|c|c|c|c|c|c|}
\hline \multirow[b]{2}{*}{ Mode } & \multicolumn{2}{|c|}{ Calculations (this work) } & \multicolumn{3}{|c|}{ Experiments (this work) } & \multicolumn{2}{|c|}{ Experiments $^{6}$} & \multirow{2}{*}{$\frac{\text { Calculations }^{30}}{\omega_{0}\left[\mathrm{~cm}^{-1}\right]}$} \\
\hline & $\omega_{0}\left[\mathrm{~cm}^{-1}\right]$ & $\mathrm{d} \omega / \mathrm{dP}\left[\mathrm{cm}^{-1} / \mathrm{GPa}\right]$ & $\omega_{0}\left[\mathrm{~cm}^{-1}\right]$ & $\partial \omega / \partial \mathrm{P}\left[\mathrm{cm}^{-1} / \mathrm{GPa}\right]$ & $\gamma\left[\mathrm{GPa}^{-1}\right]$ & $\omega_{0}\left[\mathrm{~cm}^{-1}\right]$ & $\partial \omega / \partial \mathrm{P}\left[\mathrm{cm}^{-1} / \mathrm{GPa}\right]$ & \\
\hline $\mathrm{B}_{\mathrm{g}}$ & 99.7 & -0.51 & 98 & -0.8 & -0.58 & 98 & -0.8 & 82.9 \\
\hline $\mathrm{E}_{\mathrm{g}}$ & 116.4 & 1.50 & 115 & 1.2 & 0.74 & 114 & 1.5 & 117 \\
\hline $\mathrm{E}_{\mathrm{g}}$ & 144.9 & 2.70 & 142 & 3.3 & 1.61 & 141 & 3.6 & 150.1 \\
\hline $\mathrm{B}_{\mathrm{g}}$ & 157.7 & 3.07 & 163 & 4.9 & 2.14 & 163 & 4.5 & 171.8 \\
\hline$A_{g}$ & 203.7 & 3.87 & 184 & 2.6 & 1.00 & 182 & 3.6 & 193.7 \\
\hline $\mathrm{E}_{\mathrm{g}}$ & 254.9 & 5.43 & 236 & 5.7 & 1.71 & 236 & 6 & 252.5 \\
\hline $\mathrm{B}_{\mathrm{g}}$ & 335.2 & 3.37 & 331 & 2.8 & 0.61 & 328 & 3.4 & 325.2 \\
\hline$A_{g}$ & 338.4 & 2.32 & 329 & 3.3 & 0.71 & & & 329.2 \\
\hline $\mathrm{E}_{\mathrm{g}}$ & 405.6 & 3.74 & 368 & 3.7 & 0.71 & 369 & 4.6 & 363.4 \\
\hline $\mathrm{B}_{\mathrm{g}}$ & 406.1 & 3.76 & 382 & 4.0 & 0.75 & 384 & 4.8 & 376.2 \\
\hline $\mathrm{E}_{\mathrm{g}}$ & 814.5 & 2.07 & 798 & 2.7 & 0.24 & 797 & 3.6 & 817.1 \\
\hline $\mathrm{B}_{\mathrm{g}}$ & 857.8 & 1.51 & 848 & 2.0 & 0.17 & 846 & 2.6 & 857.9 \\
\hline $\mathrm{A}_{\mathrm{g}}$ & 895.1 & 1.62 & 889 & 2.3 & 0.18 & 888 & 2.8 & 894.2 \\
\hline
\end{tabular}

In particular, the number of phonons and their frequency distribution in the spectra of the present HP phase is quite different from in the HP phase of Ref. 6. We observed 42 modes and only 13 modes are reported in Ref. 6. This fact suggests that the HP phase here detected (phase II) has a crystal structure different from the monoclinic fergusonite phase (with only 18 Raman-active modes) previously found using less hydrostatic pressure media. ${ }^{6,11}$ A candidate structure for the first HP phase found under quasi-hydrostatic conditions will be proposed in the discussion of the theoretical results (Sec. VI).

According to the present experiment, phase II remains stable up to $26 \mathrm{GPa}$, which is illustrated by the fact that the Raman spectrum continuously evolves from 17.7 to $26 \mathrm{GPa}$ (see Fig. 2(a)). In Fig. 4, it can be seen that additional changes occur at $28.8 \mathrm{GPa}$, which can be related to the

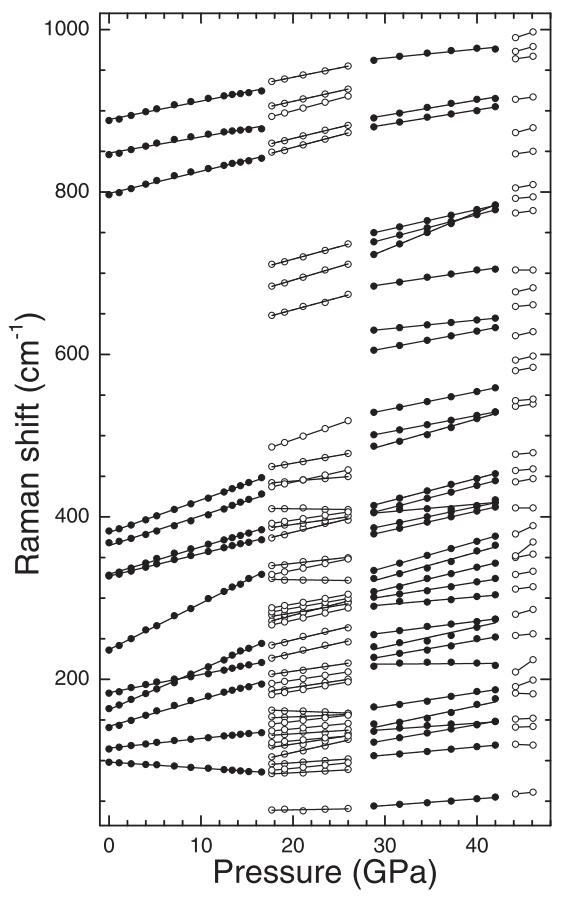

FIG. 3. Pressure evolution of the Raman modes in the different phases. occurrence of a second transition. In this case, the transformation is from phase II to phase III. The spectra assigned to phase III evolve gradually without any qualitative modification from 28.8 to $42 \mathrm{GPa}$. There are 32 Raman-active phonons in phase III. Their frequencies and pressure coefficients are summarized in Table III. In contrast with the other two phases, all the Raman modes harden upon compression. In addition, pressure coefficients tend to be a bit smaller than in the phases observed at lower pressure. The decrease of number of modes may be related to a symmetry increase of the crystal. A candidate structure for phase III will be discussed when reporting the theoretical results.

Finally, a third structural transformation is indicated by the changes observed in the Raman spectrum at 44.2 and $46.1 \mathrm{GPa}$. One of the distinctive changes is the splitting of the highest frequency mode of phase III into three modes. There are also additional Raman modes appearing near $600 \mathrm{~cm}^{-1}$. For the emergent phase IV, 35 modes are found. Since phase IV is only observed at two different pressures, we will limit the discussion to mention its possible existence and leaving its characterization to a future work. We would like to add here that evidence of neither amorphization ${ }^{33-35}$ nor chemical decompositions ${ }^{36}$ are detected in our experiments up to $46.1 \mathrm{GPa}$. Then, probably these phenomena previously reported in scheelite-type oxides could be caused by deviatoric stresses induced in previous experiments. On pressure release, all transitions were reversible with little hysteresis. Phase III was recovered at $39.1 \mathrm{GPa}$, phase II at 26.2 $\mathrm{GPa}$, and phase I (scheelite) at $15 \mathrm{GPa}$.

\section{B. Optical absorption}

Optical-absorption spectra of $\mathrm{SrMoO}_{4}$ obtained at several pressures are shown in Fig. 5. The spectra measured up to $16 \mathrm{GPa}$ resemble those reported previously at ambient conditions. ${ }^{37}$ They present a steep absorption edge plus an absorption tail at lower energies. This tail is typical of scheelite-structured oxides ${ }^{19}$ and its nature has been the subject of considerable debate, which is beyond the scope of this work. The tail overlaps partially with the fundamental 
TABLE II. Phonon frequencies $(\omega)$ and pressure coefficients $(\mathrm{d} \omega / \mathrm{dP})$ obtained from phase II $\left(P 2_{1} / n\right)$ at $17.7 \mathrm{GPa}$ compared with theoretical results for the HP monoclinic phase at $17 \mathrm{GPa}$. Mode assignment has been made on the basis of calculations.

\begin{tabular}{|c|c|c|c|c|c|c|c|c|c|}
\hline \multicolumn{2}{|c|}{ Experiments } & \multicolumn{3}{|c|}{ Calculations } & \multicolumn{2}{|c|}{ Experiments } & \multicolumn{3}{|c|}{ Calculations } \\
\hline$\omega\left[\mathrm{cm}^{-1}\right]$ & $\mathrm{d} \omega / \mathrm{dP}\left[\mathrm{cm}^{-1} / \mathrm{GPa}\right]$ & Mode & $\omega\left[\mathrm{cm}^{-1}\right]$ & $\partial \omega / \partial \mathrm{P}\left[\mathrm{cm}^{-1} / \mathrm{GPa}\right]$ & $\omega\left[\mathrm{cm}^{-1}\right]$ & $\mathrm{d} \omega / \mathrm{dP}\left[\mathrm{cm}^{-1} / \mathrm{GPa}\right]$ & Mode & $\omega\left[\mathrm{cm}^{-1}\right]$ & $\partial \omega / \partial \mathrm{P}\left[\mathrm{cm}^{-1} / \mathrm{GPa}\right]$ \\
\hline \multirow[t]{4}{*}{39} & 0.2 & $\mathrm{~A}_{\mathrm{g}}$ & 57.2 & 0.59 & 283 & 2.0 & $\mathrm{~A}_{\mathrm{g}}$ & 286.6 & 0.75 \\
\hline & & $\mathrm{B}_{\mathrm{g}}$ & 60.3 & 1.20 & 288 & 2.0 & $\mathrm{~B}_{\mathrm{g}}$ & 287.4 & 1.34 \\
\hline & & $A_{g}$ & 65.6 & 1.95 & 321 & -0.17 & $\mathrm{~A}_{\mathrm{g}}$ & 322.5 & -0.05 \\
\hline & & $\mathrm{B}_{\mathrm{g}}$ & 70.1 & 1.12 & 329 & 2.3 & $\mathrm{~B}_{\mathrm{g}}$ & 329.0 & 0.45 \\
\hline 84 & 0.6 & $\mathrm{~A}_{\mathrm{g}}$ & 84.4 & 0.95 & & & $\mathrm{~A}_{\mathrm{g}}$ & 335.5 & 1.75 \\
\hline \multirow[t]{3}{*}{88} & 1.1 & $A_{g}$ & 88.0 & 1.98 & & & $\mathrm{~B}_{\mathrm{g}}$ & 339.2 & 2.56 \\
\hline & & $\mathrm{B}_{\mathrm{g}}$ & 90.6 & 2.15 & 340 & 1.24 & $\mathrm{~A}_{\mathrm{g}}$ & 340.4 & 1.34 \\
\hline & & $\mathrm{A}_{\mathrm{g}}$ & 94.5 & 0.88 & & & $\mathrm{~B}_{\mathrm{g}}$ & 350.2 & 1.79 \\
\hline \multirow[t]{2}{*}{96} & 0.77 & $\mathrm{~B}_{\mathrm{g}}$ & 97.2 & 1.05 & 374 & 2.73 & $A_{g}$ & 380.5 & 2.66 \\
\hline & & $\mathrm{B}_{\mathrm{g}}$ & 99.8 & 2.25 & 387 & 1.58 & $\mathrm{~B}_{\mathrm{g}}$ & 389.7 & 2.45 \\
\hline \multirow[t]{2}{*}{105} & 2.54 & $\mathrm{~A}_{\mathrm{g}}$ & 105.0 & 2.65 & 392 & 1.7 & $\mathrm{~A}_{\mathrm{g}}$ & 395.2 & 1.45 \\
\hline & & $A_{g}$ & 115.4 & 1.45 & & & $\mathrm{~B}_{\mathrm{g}}$ & 396.7 & 1.23 \\
\hline 118 & 1.72 & $\mathrm{~B}_{\mathrm{g}}$ & 119.0 & 2.08 & 410 & -0.15 & $\mathrm{~A}_{\mathrm{g}}$ & 410.2 & 0.12 \\
\hline \multirow[t]{3}{*}{122} & 1.0 & $\mathrm{~B}_{\mathrm{g}}$ & 124.6 & 3.03 & & & $\mathrm{~B}_{\mathrm{g}}$ & 425.6 & 0.87 \\
\hline & & $A_{g}$ & 124.9 & 2.45 & 437 & 2.5 & $\mathrm{~B}_{\mathrm{g}}$ & 440.3 & 1.46 \\
\hline & & $\mathrm{B}_{\mathrm{g}}$ & 128.5 & 0.87 & 442 & 0.91 & $\mathrm{~A}_{\mathrm{g}}$ & 443.0 & 1.08 \\
\hline 131 & 0.76 & $A_{g}$ & 131.9 & 0.95 & 462 & 1.46 & $\mathrm{~A}_{\mathrm{g}}$ & 466.5 & 2.34 \\
\hline 137 & 1.1 & $\mathrm{~B}_{\mathrm{g}}$ & 138.5 & 3.05 & 486 & 3.9 & $\mathrm{~B}_{\mathrm{g}}$ & 480.9 & 1.87 \\
\hline \multirow[t]{2}{*}{145} & 1.3 & $\mathrm{~B}_{\mathrm{g}}$ & 145.3 & 1.34 & & & $\mathrm{~A}_{\mathrm{g}}$ & 520.5 & 2.34 \\
\hline & & $A_{g}$ & 146.4 & 0.67 & & & $\mathrm{~B}_{\mathrm{g}}$ & 535.0 & 1.89 \\
\hline 154 & 0.51 & $\mathrm{~B}_{\mathrm{g}}$ & 155.8 & 0.40 & & & $\mathrm{~A}_{\mathrm{g}}$ & 613.2 & 3.23 \\
\hline \multirow[t]{3}{*}{162} & -0.43 & $\mathrm{~A}_{\mathrm{g}}$ & 161.5 & -0.14 & & & $\mathrm{~B}_{\mathrm{g}}$ & 624.9 & 3.45 \\
\hline & & $\mathrm{B}_{\mathrm{g}}$ & 178.0 & 1.20 & & & $A_{g}$ & 628.6 & 3.76 \\
\hline & & $A_{g}$ & 179.1 & 0.45 & 648 & 3.05 & $\mathrm{~B}_{\mathrm{g}}$ & 640.3 & 2.87 \\
\hline 181 & 1.9 & $A_{g}$ & 184.5 & 2.04 & 684 & 3.33 & $\mathrm{~A}_{\mathrm{g}}$ & 695.1 & 3.13 \\
\hline 187 & 1.68 & $\mathrm{~B}_{\mathrm{g}}$ & 188.3 & 1.80 & 711 & 3.07 & $\mathrm{~B}_{\mathrm{g}}$ & 702.2 & 3.45 \\
\hline 195 & 1.7 & $\mathrm{~B}_{\mathrm{g}}$ & 198.9 & 1.56 & & & $\mathrm{~B}_{\mathrm{g}}$ & 730.8 & 3.07 \\
\hline 207 & 1.64 & $A_{g}$ & 207.4 & 1.70 & & & $A_{g}$ & 737.7 & 2.97 \\
\hline \multirow[t]{2}{*}{226} & 2.51 & $A_{g}$ & 227.5 & 2.78 & & & $\mathrm{~A}_{\mathrm{g}}$ & 745.5 & 3.23 \\
\hline & & $\mathrm{B}_{\mathrm{g}}$ & 235.0 & 1.80 & & & $\mathrm{~B}_{\mathrm{g}}$ & 780.6 & 2.56 \\
\hline \multirow[t]{3}{*}{242} & 2.68 & $\mathrm{~B}_{\mathrm{g}}$ & 245.5 & 2.88 & & & $A_{g}$ & 795.2 & 2.68 \\
\hline & & $A_{g}$ & 256.9 & 1.34 & 849 & 2.97 & $\mathrm{~B}_{\mathrm{g}}$ & 840.9 & 2.45 \\
\hline & & $\mathrm{B}_{\mathrm{g}}$ & 258.5 & 1.56 & 860 & 2.72 & $\mathrm{~A}_{\mathrm{g}}$ & 866.2 & 2.54 \\
\hline 267 & 2.5 & $A_{g}$ & 262.0 & 2.78 & 893 & 3.0 & $\mathrm{~B}_{\mathrm{g}}$ & 880.5 & 2.67 \\
\hline 272 & 2.92 & $A_{g}$ & 275.5 & 3.25 & 906 & 2.52 & $A_{g}$ & 910.7 & 3.04 \\
\hline 279 & 1.85 & $\mathrm{~B}_{\mathrm{g}}$ & 277.8 & 2.05 & 936 & 2.29 & $\mathrm{~B}_{\mathrm{g}}$ & 929.3 & 2.78 \\
\hline
\end{tabular}

absorption but it does not preclude to determine that the fundamental band gap is direct, a conclusion that is also supported by our calculations. In order to obtain quantitative information from the experiments, we will consider that the band gap is of the direct type and that the fundamental absorption edge obeys Urbach's rule. ${ }^{38,39}$

In Fig. 5, it can be seen that the band gap of $\mathrm{SrMoO}_{4}$ slightly decreases with pressure up to $16 \mathrm{GPa}$. Beyond this pressure, the sample changes from transparent to clear yellow indicating changes in the electronic structure, which are consistent with the occurrence of the structural phase transition detected in the Raman experiments. Unfortunately, the appearance of a large number of defects in the HP phase precludes the performance of accurate absorption measurements for phase II. The pressure dependence obtained for the bandgap energy $\left(\mathrm{E}_{\mathrm{g}}\right)$ in the low-pressure phase is given in Fig. 5 (inset) and its pressure coefficient $\left(\mathrm{dE}_{\mathrm{g}} / \mathrm{dP}\right)$ is $-4 \mathrm{meV} / \mathrm{GPa}$. In $\mathrm{SrWO}_{4}$, a similar behavior was found in the scheelite phase, but in this case, the band gap slightly opens with pressure. ${ }^{40}$ The cause for these differences will be discussed in Sec. V.

\section{CALCULATIONS: SCHEELITE PHASE}

We performed structural calculations considering different candidate structures. They were scheelite and the rest of structures usually considered as HP candidates for this type of materials. ${ }^{14}$ The results of our total-energy calculations for different structures are plotted in Fig. 6(a) as a function of the volume. We only plot results for the most relevant structures, i.e., tetragonal scheelite $\left(I 4_{l} / a\right),{ }^{4}$ monoclinic structure related to $\mathrm{BaWO}_{4}$-II $\left(P 2_{l} / n\right){ }^{16}$ monoclinic structure related to $\mathrm{LaTaO}_{4}\left(P 2_{I} / c\right),{ }^{41}$ and an orthorhombic structure with space group $\mathrm{Cmca}^{42}$ In agreement with experiments, the scheelite structure is found to be the most stable structure at ambient pressure. The calculated structural parameters for this phase are shown in Table IV. The agreement of the calculations with the experiments is reasonably good. The unit-cell 


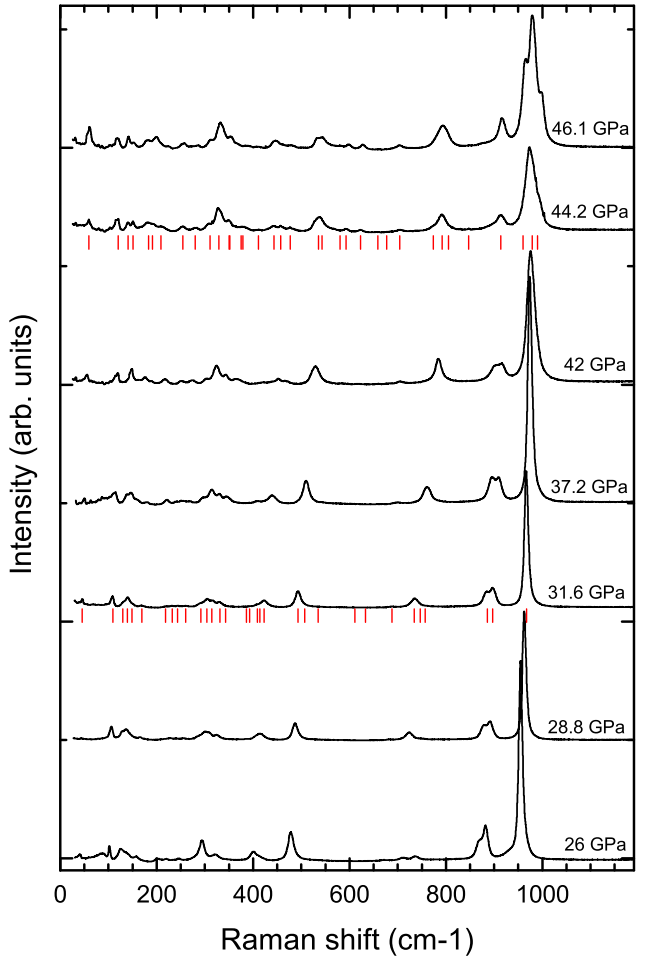

FIG. 4. Selection of Raman spectra collected from 26 to $46.1 \mathrm{GPa}$. Ticks indicate the phonons identified at 31.6 (phase III) and $44.2 \mathrm{GPa}$ (phase IV).

volume is overestimated by $2.8 \%$ and the axial ratio $c / a$ agrees within $0.3 \%$. The volume difference is typical of density-functional theory (DFT) calculations at the B3LYP level. ${ }^{43-45}$ Calculations also provide a good description of the pressure dependence of structural parameters. In particular, by fitting the energy vs. volume curve to a second-order Birch-Murnaghan $\operatorname{EOS}^{39}$ a bulk modulus $\left(\mathrm{B}_{0}\right)$ of $74.7 \mathrm{GPa}$ is obtained. This values compare quite well with the experimental $\mathrm{B}_{0}{ }^{11}$ A second-order EOS was used to obtain $\mathrm{B}_{0}$ to facilitate comparison between different structures and between experiment and calculations. We will discuss farther the structural stability of the scheelite phase, but we advance here that according to calculations it remains stable up to $16 \mathrm{GPa}$, a pressure similar to the experimental transition pressure found in Raman spectroscopy.

We have also calculated the Raman-active phonons for the scheelite structure. Results are shown in Table I and compared with experiments and previous calculations. ${ }^{30}$ When comparing calculations with experiments, differences in frequencies are of the order of $1 \%-3 \%$. There are larger differences for the modes at $366.7,380.8,183.6$, and $236.6 \mathrm{~cm}^{-1}$. For them, differences are between $6 \%$ and $10 \%$. The agreement in pressure coefficients is reasonable. In particular, our theoretical results agree better with present quasi-hydrostatic experiments than with previous experiments. ${ }^{6}$ The low-frequency $B_{g}$ mode is found to be soft as in experiments.

Regarding the band structure of the scheelite phase, the band structure is shown in Fig. 7. The valence-band maxima and conduction-band minima are located at the $\Gamma$ point of the Brillouin zone, so that this material has a direct-gap, in agreement with the absorption measurements. An important feature to note is that the dispersion of the valence band is relatively small, with comparable dispersions along the
TABLE III. Phonon frequencies $(\omega)$ and pressure coefficients $(\mathrm{d} \omega / \mathrm{dP})$ obtained from phase III at $31.6 \mathrm{GPa}$. They are compared with theoretical results obtained for the orthorhombic $\mathrm{Cmca}$ phase at $31 \mathrm{GPa}$. Mode assignment has been made on the basis of calculations.

\begin{tabular}{|c|c|c|c|c|}
\hline \multicolumn{2}{|c|}{ Experiments } & \multicolumn{3}{|c|}{ Calculations } \\
\hline$\omega\left[\mathrm{cm}^{-1}\right]$ & $\partial \omega / \partial \mathrm{P}\left[\mathrm{cm}^{-1} / \mathrm{GPa}\right]$ & Mode & $\omega\left[\mathrm{cm}^{-1}\right]$ & $\partial \omega / \partial \mathrm{P}\left[\mathrm{cm}^{-1} / \mathrm{GPa}\right]$ \\
\hline 46 & 0.83 & & & \\
\hline 109 & 1.01 & $\mathrm{~B}_{1 \mathrm{~g}}$ & 110.9 & 1.20 \\
\hline 128 & 1.95 & $\mathrm{~B}_{3 \mathrm{~g}}$ & 112.3 & 1.98 \\
\hline 139 & 0.79 & & & \\
\hline \multirow[t]{2}{*}{147} & 2.39 & $\mathrm{~A}_{\mathrm{g}}$ & 164.1 & 1.58 \\
\hline & & $\mathrm{B}_{1 \mathrm{~g}}$ & 176.5 & 0.38 \\
\hline 169 & 1.69 & $\mathrm{~B}_{2 \mathrm{~g}}$ & 187.8 & 1.11 \\
\hline 218 & 0.07 & $\mathrm{~B}_{1 \mathrm{~g}}$ & 205.9 & 0.83 \\
\hline \multirow[t]{2}{*}{232} & 1.96 & $\mathrm{~B}_{3 \mathrm{~g}}$ & 218.5 & 2.05 \\
\hline & & $\mathrm{B}_{3 \mathrm{~g}}$ & 233.8 & 0.82 \\
\hline 243 & 2.46 & $\mathrm{~A}_{\mathrm{g}}$ & 237.8 & 2.52 \\
\hline 260 & 1.40 & $\mathrm{~B}_{1 \mathrm{~g}}$ & 300.7 & 1.47 \\
\hline 292 & 0.96 & $\mathrm{~A}_{\mathrm{g}}$ & 310.5 & 0.90 \\
\hline 304 & 1.75 & $\mathrm{~B}_{2 \mathrm{~g}}$ & 310.6 & 1.34 \\
\hline 314 & 2.70 & $\mathrm{~B}_{3 \mathrm{~g}}$ & 334.9 & 1.60 \\
\hline 331 & 3.15 & $\mathrm{~B}_{1 \mathrm{~g}}$ & 347.3 & 3.05 \\
\hline 343 & 3.20 & $\mathrm{~B}_{2 \mathrm{~g}}$ & 353.3 & 2.33 \\
\hline 386 & 2.50 & $\mathrm{~B}_{1 \mathrm{~g}}$ & 385.2 & 2.72 \\
\hline 393 & 2.35 & $\mathrm{~B}_{2 \mathrm{~g}}$ & 390.1 & 2.35 \\
\hline 409 & 0.99 & $\mathrm{~A}_{\mathrm{g}}$ & 410.1 & 0.57 \\
\hline 414 & 2.93 & $\mathrm{~B}_{3 \mathrm{~g}}$ & 415.3 & 0.66 \\
\hline 423 & 0.78 & $B_{3 g}$ & 467.7 & 1.06 \\
\hline 493 & 3.21 & $B_{1 \mathrm{~g}}$ & 499.3 & 1.16 \\
\hline 507 & 2.13 & $B_{2 g}$ & 519 & 2.30 \\
\hline \multirow[t]{3}{*}{535} & 2.29 & $\mathrm{~A}_{\mathrm{g}}$ & 521.9 & 2.34 \\
\hline & & $\mathrm{A}_{\mathrm{g}}$ & 573.5 & 1.87 \\
\hline & & $B_{3 g}$ & 577.5 & 0.61 \\
\hline 611 & 2.11 & $B_{2 g}$ & 604.9 & 2.14 \\
\hline 633 & 1.12 & $\mathrm{~B}_{3 \mathrm{~g}}$ & 627.5 & 1.02 \\
\hline 688 & 1.65 & $\mathrm{~B}_{1 \mathrm{~g}}$ & 679.5 & 2.33 \\
\hline \multirow[t]{2}{*}{734} & 4.65 & $B_{3 g}$ & 733.5 & 1.11 \\
\hline & & $\mathrm{A}_{\mathrm{g}}$ & 743.5 & 0.95 \\
\hline 747 & 2.98 & $\mathrm{~B}_{2 \mathrm{~g}}$ & 745.7 & 3.12 \\
\hline \multirow[t]{2}{*}{757} & 2.55 & $\mathrm{~B}_{1 \mathrm{~g}}$ & 760.4 & 2.77 \\
\hline & & $\mathrm{A}_{\mathrm{g}}$ & 773 & 1.58 \\
\hline 886 & 1.82 & $B_{3 g}$ & 780.9 & 2.28 \\
\hline 897 & 1.89 & $\mathrm{~A}_{\mathrm{g}}$ & 846.5 & 0.23 \\
\hline 967 & 1.11 & $\mathrm{~B}_{3 \mathrm{~g}}$ & 892.9 & 1.31 \\
\hline
\end{tabular}

different directions. The band-gap energy $\left(E_{g}\right)$ at ambient pressure is overestimated by calculations, $5.35 \mathrm{eV}$ versus $4.2 \mathrm{eV}$. Previous DFT calculations performed using the ABINIT code gave an underestimated value for $\mathrm{Eg}$ $(3.58 \mathrm{eV}) .{ }^{19}$ These differences between calculations and experiments are typical of DFT calculations. ${ }^{22,40-46}$ However, they usually describe well the pressure dependence of $E_{g}$.

In Fig. 7, we also show the projected density of states (DOS) on atomic orbitals. The top of the valence band is mainly formed by $\mathrm{O} 2 p$ orbitals, and the bottom of the conduction bands predominantly consists of Mo $4 d$ states. There is a first conduction band formed mainly by Mo $4 d_{z}{ }^{2}$ and a second conduction band has mostly the Mo $4 d_{x z}, 4 d_{y z}$, and $4 d_{x y}$ nature. Under compression, the $\mathrm{O}$ states move faster 


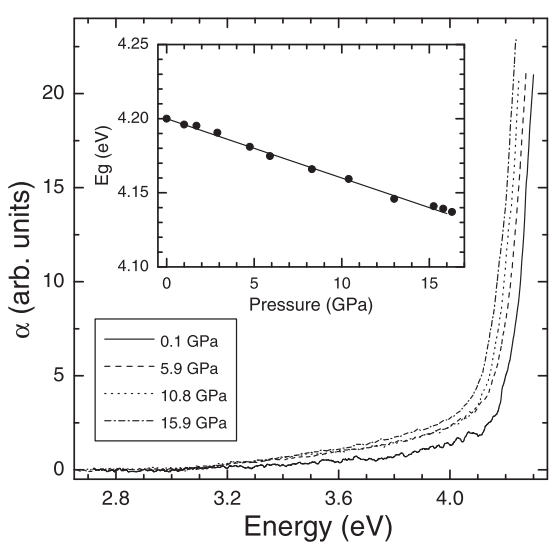

FIG. 5. Absorption spectra as a function of pressure. The inset shows the pressure dependence of the band-gap energy.

towards higher energies than the Mo states, producing a small reduction of $\mathrm{E}_{\mathrm{g}}$. We estimate $\mathrm{dE}_{\mathrm{g}} / \mathrm{dP}=-4 \mathrm{meV} / \mathrm{GPa}$, in agreement with our experiments. We would like to comment here that the same behavior was obtained for $\mathrm{SrWO}_{4} \cdot{ }^{40}$ However, in this compound, experiments found that the gap slightly opens under compression. The agreement found here for $\mathrm{SrMoO}_{4}$ points that small subtle changes induced in the crystal structure by non-hydrostatic conditions in $\mathrm{SrWO}_{4}$ could be a possible reason of the sign difference found in $\mathrm{dE}_{\mathrm{g}} / \mathrm{dP}$.

\section{CALCULATIONS: PROPOSED HP PHASES}

Among the candidate structures for HP phase, we have considered the M-fergusonite structure (I2/a), which has been experimentally found beyond $13 \mathrm{GPa}$ by x-ray diffraction in a non-hydrostatic pressure medium. ${ }^{11}$ At low pressures, we cannot discriminate between the fergusonite and the scheelite structures. Basically, fergusonite-a monoclinic
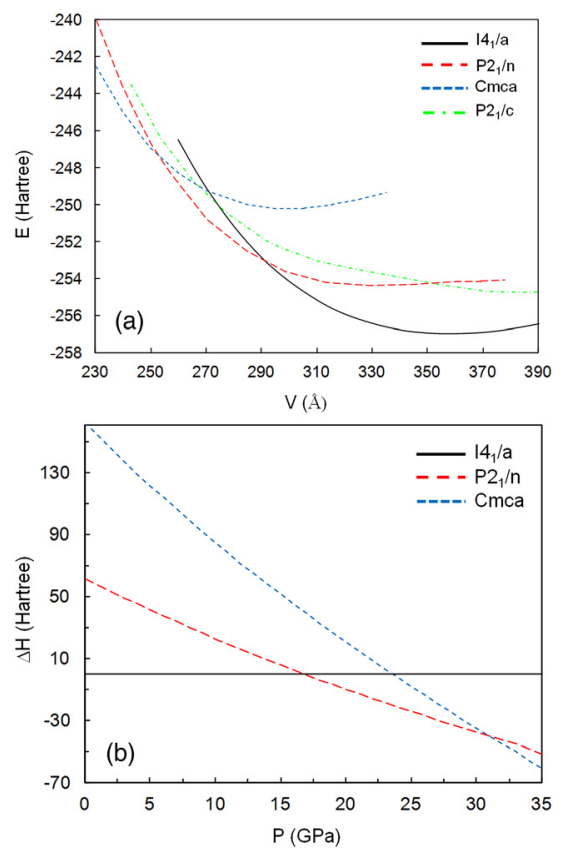

FIG. 6. (a) Total energy versus volume for different structures. (b) Enthalpy difference with respect to the scheelite structure versus pressure. distorted version of scheelite-reduces to the scheelite structure after structural optimization. Beyond $16 \mathrm{GPa}$, we are able to discriminate between scheelite and fergusonite and found that fergusonite is thermodynamically favored among those structures considered in the calculations. However, total energy and free energy differences (less than $0.1 \%$ in favor of fergusonite beyond $16 \mathrm{GPa}$ ) are comparable with the accuracy of calculations. Total energies and enthalpies of the scheelite and fergusonite structure are compared for the region of interest in Fig. 8. According to these results, fergusonite becomes slightly more stable than scheelite at $16 \mathrm{GPa}$. The calculated structural parameters for the fergusonite phase at $16 \mathrm{GPa}$ are given in Table IV. They are similar to those reported in Ref. 11 at $13.1 \mathrm{GPa}$. However, as we mentioned above, the monoclinic fergusonite structure cannot explain the changes observed in the Raman spectrum at the first phase transition. In particular, more than three times the number of Raman modes expected for fergusonite is detected in phase II. Therefore, we have considered other potential structures for phase II.

At $17 \mathrm{GPa}$, a clear transition to a monoclinic structure belonging to space group $P 2_{1} / n$, and related to $\mathrm{BaWO}_{4}$-II, can be seen in Fig. 6. Beyond $17 \mathrm{GPa}$, this structure becomes more stable than scheelite and fergusonite. This transition pressure agrees well with that found in the present experiments. The stabilization of the $P 2_{1} / n$ structure at a pressure very similar to the calculated scheelite-fergusonite transition and the facts described above regarding the thermodynamic stability of fergusonite suggests that it was observed previously $^{6,11}$ probably as a metastable phase favored by deviatoric stresses. The structure of this monoclinic phase is shown in Fig. 1(b). The transition to this structure involves a volume collapse of $6.9 \%$ and implies an increase of the coordination of the $\mathrm{Sr}$ cation from 8 in scheelite to $7+3$ or $9+3$ in phase II for $\mathrm{Sr}_{2}$ and $\mathrm{Sr}_{1}$, respectively. In addition, there is an increase of the coordination of the Mo cation from 4 in scheelite to 6 in phase II. Similar structures have been found as post-scheelite phases in related compounds. ${ }^{16,47,48}$ The monoclinic HP phase consists of layers of corner-linked $\mathrm{MoO}_{6}$ octahedra connected by strontium atoms located between them. The $\mathrm{MoO}_{6}$ octahedra are distorted and the molybdenum atoms are slightly shifted from their centers. The structural parameters of the HP monoclinic phase are summarized in Table IV. According to our calculations, the interatomic bond distances considerably change at the transition leading to an increase of the packing efficiency of the HP phase and to a compressibility decrease (the bulk modulus increases by $17.5 \%$ ).

Regarding the crystal structure of phase II, previously assigned to the monoclinic fergusonite structure, we have considered the possibility of an incorrect assignment of the crystal space group during the analysis of XRD data in Ref. 11. However, this possibility has been ruled out by the comparison of theoretically calculated positions of Bragg peaks for the monoclinic structure with space group $P 2_{1} / n$ with those obtained after indexing the measured diffraction pattern from fergusonite-type $(\mathrm{I} / \mathrm{a}) \mathrm{SrMoO}_{4} \cdot{ }^{11}$ This comparison is made in Fig. 9. There it can be seen that, as shown in Ref. 11, the measured diffraction pattern can be well indexed 
TABLE IV. Calculated structural parameters of $\mathrm{SrMoO}_{4}$ phases. Scheelite structure at $\mathrm{P}=0 \mathrm{GPa}$, Fergusonite-type at $16 \mathrm{GPa}, \mathrm{BaWO}$-II type at $17 \mathrm{GPa}$, and $\mathrm{Cmca}$ at $31 \mathrm{GPa}$. The bulk modulus and its pressure derivative for each phase are also given.

\begin{tabular}{|c|c|c|c|c|}
\hline & Site & $\mathrm{x}$ & y & $\mathrm{z}$ \\
\hline \multicolumn{5}{|c|}{ Scheelite $I 4_{l} / a: a=5.448 \AA, c=12.112 \AA, \mathrm{B}_{0}=74.7 \mathrm{GPa}$, and $\mathrm{B}_{0}{ }^{\prime}=4$} \\
\hline $\mathrm{Sr}$ & $4 \mathrm{~b}$ & 0 & 0.25 & 0.625 \\
\hline Mo & $4 \mathrm{a}$ & 0 & 0.25 & 0.125 \\
\hline $\mathrm{O}$ & $16 \mathrm{f}$ & 0.2371 & 0.1113 & 0.0433 \\
\hline \multicolumn{5}{|c|}{ Fergusonite $I 2 / a: a=5.233 \AA, b=11.196 \AA, c=5.180 \AA, \beta=90.7^{\circ}, \mathrm{B}_{0}=84.2 \mathrm{GPa}$, and $\mathrm{B}_{0}{ }^{\prime}=4$} \\
\hline $\mathrm{Sr}$ & $4 \mathrm{e}$ & 0.25 & 0.6250 & 0 \\
\hline Mo & $4 \mathrm{e}$ & 0.25 & 0.1237 & 0 \\
\hline $\mathrm{O}_{1}$ & $8 \mathrm{f}$ & 0.9122 & 0.9632 & 0.2342 \\
\hline $\mathrm{O}_{2}$ & $8 \mathrm{f}$ & 0.4851 & 0.2129 & 0.8402 \\
\hline \multicolumn{5}{|c|}{$\mathrm{BaWO}_{4}$-II type $P 2_{1} / n: a=12.042 \AA, b=6.710 \AA, c=7.039 \AA, \beta=91.02^{\circ}, \mathrm{B}_{0}=87.8 \mathrm{GPa}$, and $\mathrm{B}_{0}{ }^{\prime}=4$} \\
\hline $\mathrm{Sr}_{1}$ & $4 \mathrm{e}$ & 0.1502 & 0.6589 & 0.1618 \\
\hline $\mathrm{Sr}_{2}$ & $4 \mathrm{e}$ & 0.1312 & 0.9500 & 0.6301 \\
\hline $\mathrm{Mo}_{1}$ & $4 \mathrm{e}$ & 0.0881 & 0.1671 & 0.0887 \\
\hline $\mathrm{Mo}_{2}$ & $4 \mathrm{e}$ & 0.1035 & 0.4600 & 0.6390 \\
\hline $\mathrm{O}_{1}$ & $4 \mathrm{e}$ & 0.0921 & 0.0316 & 0.3066 \\
\hline $\mathrm{O}_{2}$ & $4 \mathrm{e}$ & 0.1982 & 0.6065 & 0.7749 \\
\hline $\mathrm{O}_{3}$ & $4 \mathrm{e}$ & 0.0480 & 0.6593 & 0.4755 \\
\hline $\mathrm{O}_{4}$ & $4 \mathrm{e}$ & 0.2234 & 0.2821 & 0.0802 \\
\hline $\mathrm{O}_{5}$ & $4 \mathrm{e}$ & 0.0690 & 0.2565 & 0.8052 \\
\hline $\mathrm{O}_{6}$ & $4 \mathrm{e}$ & 0.1902 & 0.3388 & 0.4757 \\
\hline $\mathrm{O}_{7}$ & $4 \mathrm{e}$ & 0.0146 & 0.3894 & 0.1659 \\
\hline $\mathrm{O}_{8}$ & $4 \mathrm{e}$ & 0.0850 & 0.9177 & 0.9557 \\
\hline \multicolumn{5}{|c|}{ Orthorhombic $C m c a: a=7.505 \AA, b=12.529 \AA, c=5.106 \AA, \mathrm{B}_{0}=104.5 \mathrm{GPa}$, and $\mathrm{B}_{0}{ }^{\prime}=4$} \\
\hline $\mathrm{Sr}$ & $8 \mathrm{e}$ & 0.25 & 0.8345 & 0.25 \\
\hline Mo & $8 \mathrm{f}$ & 0 & 0.5885 & 0.2751 \\
\hline $\mathrm{O}_{1}$ & $8 \mathrm{e}$ & 0.25 & 0.1435 & 0.25 \\
\hline $\mathrm{O}_{2}$ & $8 \mathrm{f}$ & 0 & 0.7919 & 0.9656 \\
\hline $\mathrm{O}_{3}$ & $8 \mathrm{~d}$ & 0.1504 & 0 & 0 \\
\hline $\mathrm{O}_{4}$ & $8 \mathrm{f}$ & 0 & 0.9173 & 0.4206 \\
\hline
\end{tabular}

with the fergusonite $(I 2 / a)$ structure. The pattern calculated for monoclinic $P 2_{l} / n$ is totally different. In particular, the number of reflections increases around 4 times, there are many reflections at low angles not expected for fergusonite, and instead of the strongest peak of fergusonite (near $2 \theta=8^{\circ}$ ) there are clearly five reflections for the monoclinic $P 2_{1} / n$ structure. Therefore, there is no doubt the phase observed in non-hydrostatic experiments (fergusonite) cannot be assigned to the structure obtained under hydrostatic conditions $\left(P 2_{1} / n\right)$.

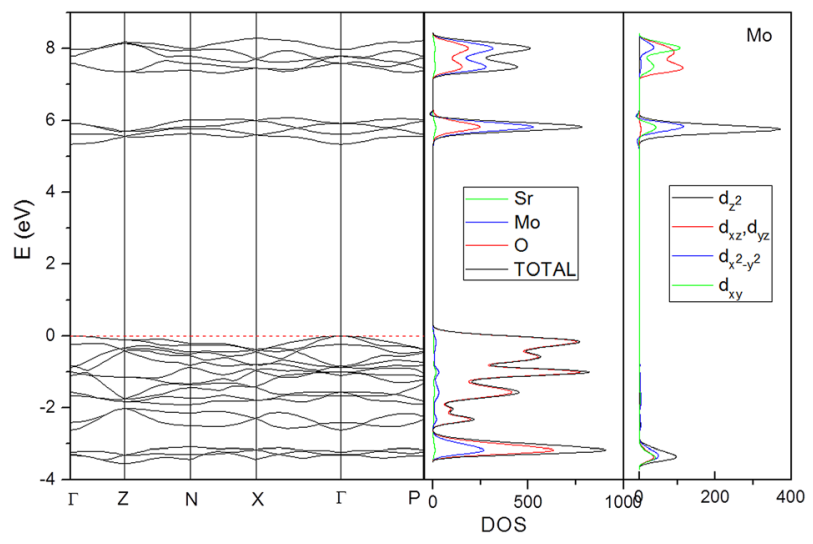

FIG. 7. Band structure, total and partial DOS for scheelite-type $\mathrm{SrMoO}_{4}$.
The Raman spectra assigned to phase II resemble very much to those previously reported for the $\mathrm{BaWO}_{4}$-II phase supporting our ab initio calculations findings. The proposed monoclinic HP structure is centrosymmetric and has space group $P 2_{1} / n\left(C^{5}{ }_{2 h}\right)$. Group theory leads to the existence of 72 Raman active modes: $\Gamma=36 \mathrm{~A}_{\mathrm{g}}+36 \mathrm{~B}_{\mathrm{g}}$. The calculated modes and their pressure coefficients are shown in Table II. Raman frequencies compare better than pressure coefficients, in particular, for the low-frequency modes. The monoclinic HP structure has more Raman modes than observed. The experimental assignment of the mode symmetry in the HP monoclinic phase is difficult because of the lack of the depolarization of the diamond anvils at high pressure, and because the number of modes that can be clearly resolved in the experimental Raman spectra beyond the transition pressure is 42. Something similar is observed in $\mathrm{BaWO}_{4}$-II, where a smaller number of modes than here are measured. ${ }^{16}$ The non-detection of all expected modes can be due to limited spectral resolution, since many peaks may be very close to each another, as evidenced by our calculations and/or to the small scattering cross section of some modes. In spite of these facts, the reasonable description given by theory for most of the observed Raman modes (finding also soft modes), the total-energy results, and the existence of HP phases isomorphic to $\mathrm{BaWO}_{4}$-II in other scheelites indicate 


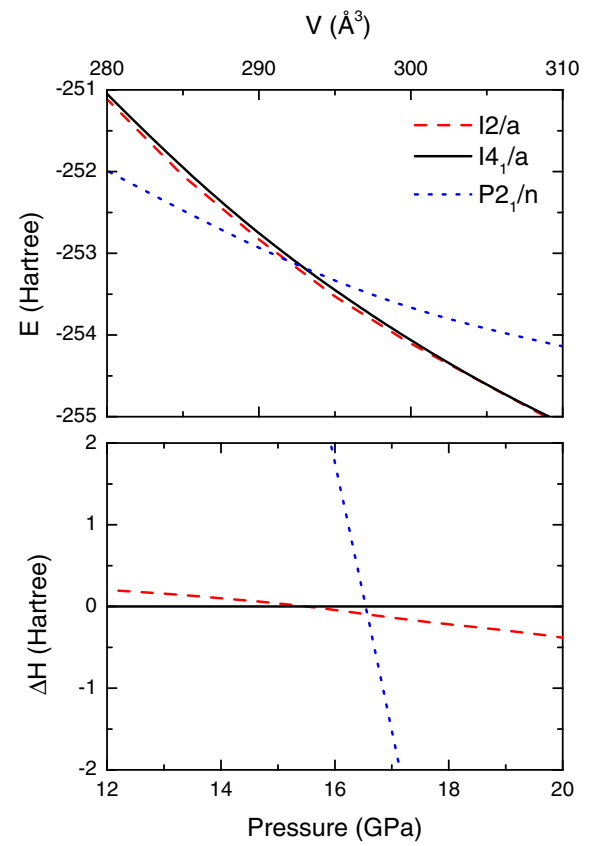

FIG. 8. Total energy versus volume for scheelite $\left(I 4_{l} / \mathrm{a}\right)$, fergusonite $(I 2 / a)$, and new HP monoclinic $\left(P 2_{1} / n\right)$ structures (top). Enthalpy difference between the same three structures versus pressure (bottom). In order to show the small differences, only the pressure and volume regions of interest are shown. Note that the theoretical range of stability of fergusonite is very small.

that phase II is probably the proposed monoclinic phase. To unequivocally solve this structure, $\mathrm{x}$-ray diffraction studies in quasi-hydrostatic pressure medium such as those reported for $\mathrm{BaWO}_{4}$ will be needed. ${ }^{16}$

For completeness, we have also calculated the Raman modes of the fergusonite structure. Frequencies are reported in Table $\mathrm{V}$ together with the pressure coefficients. The frequencies are compared with those experimentally found under non-hydrostatic conditions. The agreement in the frequencies is good, confirming than non hydrostaticity favors the scheelite-fergusonite transition.

Fig. 6 shows that our calculations predict the occurrence of a second transition at $31 \mathrm{GPa}$, which is close to the pressure of the second experimental transition. The second transition is to an orthorhombic structure ( $\mathrm{Cmca}$ ) that has been previously predicted as a HP phase for $\mathrm{CaWO}_{4}$ and $\mathrm{SrWO}_{4}{ }^{42}$ The structure is illustrated in Fig. 1(c) and its structural parameters at $31 \mathrm{GPa}$ are summarized in Table IV. Volume change at the transition is $7 \%$. This orthorhombic structure is more compact than the monoclinic HP structure and the bulk modulus is enhanced by $19 \%$. Regarding atomic coordination, the second transition implies a change of the coordination of the Sr cation from $7+3$ or $9+3$ in the monoclinic structure to 11 in orthorhombic structure. Also, there is an increase of the coordination of the Mo cation from 6 to $6+1$.

The Raman modes calculated for the orthorhombic Cmca structure are shown in Table III and compared with experiments. The orthorhombic structure has 36 Raman active modes: $\Gamma=9 \mathrm{~A}_{\mathrm{g}}+9 \mathrm{~B}_{1 \mathrm{~g}}+7 \mathrm{~B}_{2 \mathrm{~g}}+11 \mathrm{~B}_{3 \mathrm{~g}}$. Thus, it implies a reduction of Raman modes as observed in experiments. The calculated modes and their pressure coefficients are summarized in Table III. Comparison with experiments is similar to that for phase II. The main differences are observed for the

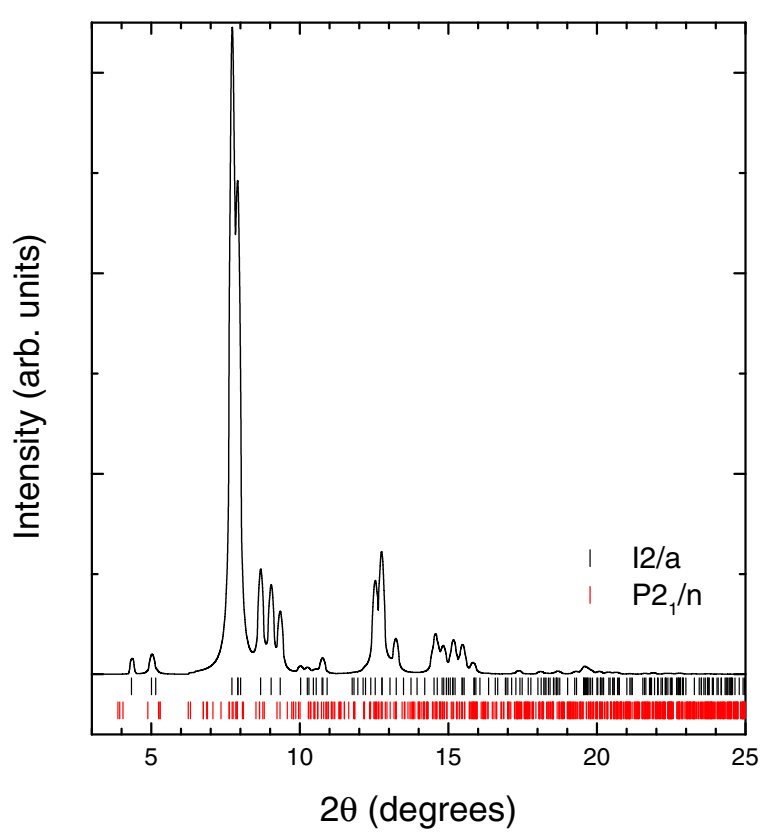

FIG. 9. XRD pattern measured at $18.8 \mathrm{GPa}$ (Ref. 11) indexed with the monoclinic fergusonite $(I 2 / a)$ compared with calculated Bragg peaks of monoclinic $P 2_{1} / n$ structure $(\lambda=0.41414 \AA)$. Ticks show the position of Bragg peaks.

highest frequency modes and the lowest frequency modes. In particular, a mode is measured at $46 \mathrm{~cm}^{-1}$ while calculated modes have frequencies larger than $110.9 \mathrm{~cm}^{-1}$. A possible reason for this discrepancy could be the non inclusion of anharmonic effects in the calculations. Other possibility is that the observed discrepancies indicate that $\mathrm{Cmca}$ is not the correct space group for phase III. Obviously, our results are calling for new $\mathrm{x}$-ray diffraction experiments to accurately determine the crystal structures of the new HP structures reported here.

\section{CONCLUDING REMARKS}

We studied $\mathrm{SrMoO}_{4}$ under quasi-hydrostatic high pressure up to $46.1 \mathrm{GPa}$ by Raman spectroscopy and optical-absorption experiments. Both experimental techniques show that no phase transition takes place up to $16 \mathrm{GPa}$, when the experiment is performed under quasi-hydrostatic conditions. Upon further compression, we found evidence of two reversible phase transitions at 17.7 and $28.8 \mathrm{GPa}$ and the onset of a third one is detected at $44.2 \mathrm{GPa}$. None of the transitions is to the monoclinic fergusonite phase previously found under less hydrostatic conditions. ${ }^{6,11}$ We also studied $\mathrm{SrMoO}_{4}$ by $a b$ initio calculations. Calculations describe precisely the evolution of the crystal structure of the low-pressure phase and help to understand the electronic and lattice-dynamical properties of scheelite-type $\mathrm{SrMoO}_{4}$. Calculations predict the occurrence of two phase transitions: the first one to a monoclinic structure $\left(P 2_{1} / n\right)$ and the second one to an orthorhombic structure ( $\mathrm{Cmca}$ ). Both transitions involve a volume collapse, an atomic coordination increase, and a compressibility decrease. The Raman spectrum calculated for the HP monoclinic phase is compatible with the one measured for the first HP phase. This fact and the existence of a similar HP 
TABLE V. Calculated phonon frequencies $(\omega)$ and pressure coefficients $(\mathrm{d} \omega / \mathrm{dP})$ for fergusonite at $17 \mathrm{GPa}$. They are compared with experimental frequencies measured at $15.5 \mathrm{GPa}$ under non hydrostatic conditions. ${ }^{6}$ Mode assignment has been made on the basis of calculations.

\begin{tabular}{|c|c|c|c|}
\hline \multirow[b]{2}{*}{ Mode } & \multicolumn{2}{|c|}{ Calculations (this work) } & \multirow{2}{*}{$\frac{\text { Experiments }^{6}}{\omega\left[\mathrm{cm}^{-1}\right]}$} \\
\hline & $\omega\left[\mathrm{cm}^{-1}\right]$ & $\mathrm{d} \omega / \mathrm{dP}\left[\mathrm{cm}^{-1} / \mathrm{GPa}\right]$ & \\
\hline $\mathrm{A}_{\mathrm{g}}$ & 99.7 & -0.25 & 95 \\
\hline $\mathrm{B}_{\mathrm{g}}$ & 131.0 & 0.49 & 124 \\
\hline $\mathrm{B}_{\mathrm{g}}$ & 132.2 & 0.47 & 132 \\
\hline $\mathrm{B}_{\mathrm{g}}$ & 192.3 & 0.86 & 158 \\
\hline $\mathrm{B}_{\mathrm{g}}$ & 193.0 & 0.85 & 190 \\
\hline $\mathrm{A}_{\mathrm{g}}$ & 217.3 & 0.90 & \\
\hline$A_{g}$ & 247.5 & 0.98 & 267 \\
\hline $\mathrm{B}_{\mathrm{g}}$ & 310.0 & 1.76 & \\
\hline $\mathrm{B}_{\mathrm{g}}$ & 313.6 & 1.68 & \\
\hline $\mathrm{A}_{\mathrm{g}}$ & 367.1 & 1.02 & 369 \\
\hline$A_{g}$ & 385.0 & 0.99 & 383 \\
\hline $\mathrm{A}_{\mathrm{g}}$ & 422.5 & 1.42 & \\
\hline $\mathrm{B}_{\mathrm{g}}$ & 439.9 & 1.48 & \\
\hline $\mathrm{B}_{\mathrm{g}}$ & 445.3 & 1.33 & 459 \\
\hline $\mathrm{B}_{\mathrm{g}}$ & 847.0 & 0.77 & $680-707$ \\
\hline $\mathrm{B}_{\mathrm{g}}$ & 849.8 & 0.78 & 854 \\
\hline $\mathrm{A}_{\mathrm{g}}$ & 884.4 & 0.59 & \\
\hline$A_{g}$ & 931.4 & 0.55 & 929 \\
\hline
\end{tabular}

phase in other scheelites support that the proposed phase is likely the experimentally observed phase. However, to unequivocally assign the structure of HP phases, $\mathrm{x}$-ray diffraction experiments have to be performed using quasi-hydrostatic pressure media since we found that non-hydrostaticity could strongly influence the HP structural sequence of $\mathrm{SrMoO}_{4}$.

\section{ACKNOWLEDGMENTS}

This research was carried out with the financial support of the Spanish MINECO (Grant Nos. MAT2010-21270C04-01 and CSD2007-00045). L.G. acknowledges the MALTA-Consolider Ingenio 2010 Team and the Servei Informatica of Universitat Jaume I for a generous allotment of computer time.

${ }^{1}$ J. C. Sczancoski, L. S. Cavalcante, M. R. Joya, J. A. Varela, P. S. Pizani, and E. Longo, J. Chem. Eng. 140, 632 (2008).

${ }^{2}$ S. B. Mikhrin, A. N. Mishin, A. S. Potapov, P. A. Rodnyi, and A. S. Voloshinovskii, Nucl. Instrum. Methods Phys. Res. A 486, 295 (2002).

${ }^{3}$ J. Bi, L. Wu, Y. Zhang, Z. Li, J. Li, and X. Fu, Appl. Catal. B: Environmental 91, 135 (2009).

${ }^{4}$ A. W. Sleight, Acta Crystallogr. B 28, 2899 (1972).

${ }^{5}$ R. M. Hazen, L. W. Finger, and J. W. E. Mariathasan, J. Phys. Chem. Solids 46, 253 (1985).

${ }^{6}$ A. Jayaraman, S. Y. Wang, S. R. Shieh, S. K. Sharma, and L. C. Ming, J. Raman Spectrosc. 26, 451 (1995).

${ }^{7}$ D. Christofilos, G. A. Kourouklis, and S. Ves, J. Phys. Chem. Solids 56, 1125 (1995).

${ }^{8}$ S. R. Shieh, L. C. Ming, and A. Jayaraman, J. Phys. Chem. Solids 57, 205 (1996).

${ }^{9}$ W. A. Crichton and A. Grzechnik, Z. Kristallogr. 219, 337 (2004).

${ }^{10}$ A. Christofilos, J. Arvanitidis, E. Kampasakali et al., Phys. Status Solidi B 241, 3155 (2004).

${ }^{11}$ D. Errandonea, R. S. Kumar, X. Xinghua, and C. Tu, J. Solid State Chem. 181, 355 (2008).

${ }^{12}$ D. Errandonea, D. Santamaria-Perez, V. Grover, S. N. Achary, and A. K. Tyagi, J. Appl. Phys. 108, 073518 (2010).
${ }^{13}$ D. Errandonea, D. Santamaria-Perez, S. N. Achary, A. K. Tyagi, P. Gall, and P. Gougeon, J. Appl. Phys. 109, 043510 (2011).

${ }^{14}$ D. Errandonea and F. J. Manjon, Prog. Mater. Sci. 53, 711 (2008).

${ }^{15}$ S. Klotz, J. C. Chervin, P. Munsch, and G. Le Marchand, J. Phys. D: Appl. Phys. 42, 075413 (2009).

${ }^{16}$ O. Gomis, J. A. Sanz, R. Lacomba-Perales, D. Errandonea, Y. Meng, J. C. Chervin, and A. Polian, Phys. Rev. B 86, 054121 (2012).

${ }^{17}$ J. Ruiz-Fuertes, D. Errandonea, R. Lacomba-Perales, A. Segura, J. Gonzalez, F. Rodriguez, F. J. Manjon, S. Ray, P. Rodriguez-Hernandez, A. Muñoz, Z. Zhu, and C. Tu, Phys. Rev. B 81, 224115 (2010).

${ }^{18}$ H. K. Mao, J. Xu, and P. M. Bell, J. Geophys. Res. 91, 4673, doi:10.1029/ JB091iB05p04673 (1986).

${ }^{19}$ R. Lacomba-Perales, J. Ruiz-Fuertes, D. Errandonea, D. Martinez-Garcia, and A. Segura, EPL 83, 37002 (2008).

${ }^{20}$ A. Segura, J. A. Sanz, D. Errandonea, D. Martinez-Garcia, and V. Fages, Appl. Phys. Lett. 88, 011910 (2006).

${ }^{21}$ D. Errandonea, D. Martinez-Garcia, R. Lacomba-Perales, J. Ruiz-Fuertes, and A. Segura, Appl. Phys. Lett. 89, 091913 (2006).

${ }^{22}$ V. Panchal, D. Errandonea, A. Segura, P. Rodrıguez-Hernandez, A. Muñoz, S. Lopez-Moreno, and M. Bettinelli, J. Appl. Phys. 110, 043723 (2011).

${ }^{23}$ R. Dovesi, V. R. Saunders, C. Roetti, R. Orlando, C. M. Zicovich-Wilson, F. Pascale, B. Civalleri, K. Doll, N. M. Harrison, I. J. Bush, Ph. D’Arco, and M. Llunell, CRYSTAL09 User's Manual (University of Torino, 2009); CRYSTAL09 Program, Torino, Italy, 2010.

${ }^{24}$ A. Becke, J. Chem. Phys. 98, 5648 (1993).

${ }^{25}$ C. Lee, W. Yang, and R. G. Parr, Phys. Rev. B 37, 785 (1988).

${ }^{26}$ C. H. Hu and D. P. Chong, Encyclopedia of Computational Chemistry (Wiley, Chichester, 1998), Vol. 1.

${ }^{27}$ L. Gracia, A. Beltrán, and D. Errandonea, Phys. Rev. B 80, 094105 (2009).

${ }^{28}$ L. Gracia, A. Beltrán, and J. Andrés, J. Phys. Chem. C 115, 7740 (2011).

${ }^{29}$ F. Birch, J. Geophys. Res. 83, 1257, doi:10.1029/JB083iB03p01257 (1978).

${ }^{30}$ R. Vali, Comput. Mater. Sci. 50, 2683 (2011).

${ }^{31}$ D. Errandonea and F. J. Manjon, Mater. Res. Bull. 44, 807 (2009).

${ }^{32}$ B. Minisini, L. El Hadj, M. Lontsi Fomena, N. Van Garderen, and F. Tsobnang, J. Phys. Condens. Matter 18, 2429 (2006).

${ }^{33}$ A. Jayaraman, S. Y. Wang, and S. K. Sharma, Solid State Commun. 93, 885 (1995).

${ }^{34}$ D. Errandonea, M. Somayazulu, and D. Häusermann, Phys. Status Solidi B 235, 162 (2003)

${ }^{35}$ D. Errandonea, J. Pellicer-Porres, F. J. Manjon, A. Segura, Ch. FerrerRoca, R. S. Kumar, O. Tschauner, J. Lopez-Solano, P. RodriguezHernandez, S. Radescu, A. Mujica, A. Munoz, and G. Aquilanti, Phys. Rev. B 73, 224103 (2006).

${ }^{36}$ A. Grzechnik, W. A. Crichton, and M. Hanfland, Phys. Status Solidi B 242, 2795 (2005)

${ }^{37} \mathrm{M}$. W. Stoltzfus, "Structure-property relationships in solid state materials: A computational approach emphasizing chemical bonding," Ph.D. dissertation (Ohio State University, 2007).

${ }^{38}$ J. Ruiz-Fuertes, D. Errandonea, F. J. Manjon, D. Martinez-Garcia, A. Segura, V. V. Ursaki, and I. M. Tiginyanu, J. Appl. Phys. 103, 063710 (2008).

${ }^{39}$ F. Urbach, Phys. Rev. 92, 1324 (1953).

${ }^{40}$ R. Lacomba-Perales, D. Errandonea, A. Segura, J. Ruiz-Fuertes, P. RodriguezHernandez, S. Radescu, J. Lopez-Solano, A. Mujica, and A. Muñoz, J. Appl. Phys. 110, 043703 (2011).

${ }^{41}$ Y. A. Titov, A. M. Sych, A. N. Sokolov, A. A. Kapshuk, V. Ya Markiv, and N. M. Belyavina, J. Alloys Compd. 311, 252 (2000).

${ }^{42}$ D. Errandonea, J. Pellicer-Porres, F. J. Manjón, A. Segura, Ch. FerrerRoca, R. S. Kumar, O. Tschauner, P. Rodríguez-Hernández, J. LópezSolano, S. Radescu, A. Mujica, A. Muñoz, and G. Aquilanti, Phys. Rev. B 72, 174106 (2005).

${ }^{43}$ D. Errandonea, R. S. Kumar, L. Gracia, A. Beltrán, S. N. Achary, and A. K. Tyagi, Phys. Rev. B 80, 094101 (2009).

${ }^{44}$ D. Errandonea, L. Gracia, A. Beltrán, A. Vegas, and Y. Meng, Phys. Rev. B 84, 064103 (2011).

${ }^{45}$ L. Gracia, A. Beltran, D. Errandonea, and J. Andres, Inorg. Chem. 51, 1751 (2012)

${ }^{46}$ J. Ruiz-Fuertes, S. Lopez-Moreno, J. Lopez-Solano, D. Errandonea, A. Segura, R. Lacomba-Perales, A. Muñoz, S. Radescu, P. RodrıguezHernandez, M. Gospodinov, L. L. Nagornaya, and C. Y. Tu, Phys. Rev. B 86, 125202 (2012)

${ }^{47}$ I. Kawada, K. Kato, and T. Fujita, Acta Crystallogr. B 30, 2069 (1974).

${ }^{48}$ P. W. Richter, G. J. Kruger, and C. W. F. T. Pistorius, Acta Crystallogr. B 32, 928 (1976). 